PARTICIPACIÓN CIUDADANA Y RESPONSABILIDAD SOCIAL PARA EL DESARROLLO SUSTENTABLE

\title{
PARTICIPACIÓN CIUDADANA Y RESPONSABILIDAD SOCIAL \\ PARA EL DESARROLLO SUSTENTABLE
}

\section{CITIZEN PARTICIPATION AND SOCIAL RESPONSIBILITY FOR SUSTAINABLE DEVELOPMENT}

\author{
Liliana Amador Angón*, Jorge Isaac Sarquís Ramírez**,

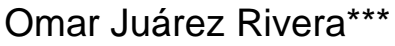

\footnotetext{
* Ingeniero Industrial. Experto en Sistemas de Gestión de la Calidad. Facultad de Contaduría y Administración UV.

** Profesor-Investigador. Facultad de Contaduría. Universidad Veracruzana Campus Orizaba/Córdoba en Ixtac. Investigador de la Universidad Veracruzana en la Facultad de Contaduría y Administración. Email: jsarquis@uv.mx

*** Doctorado en Economía. Facultad de Contaduría y Administración UV. LAE, Profesor titular de tiempo completo. Email: ojuarez@uv.mx
}

Dirección para recibir correspondencias: lilianaamador@yahoo.com.mx 
PARTICIPACIÓN CIUDADANA Y RESPONSABILIDAD SOCIAL PARA EL DESARROLLO SUSTENTABLE

\section{RESUMEN}

Este ensayo, presenta una serie de argumentos que pretenden contribuir a la construcción teórica de la participación ciudadana, responsable como objeto de estudio en relación a la sustentabilidad del desarrollo. Sostenemos que la responsabilidad ciudadana individual es requisito sine qua non para poder exigir responsabilidad social empresarial; asimismo sostenemos que el poder político representativo ha agotado sus posibilidades de orientar del mejor modo el tema económico y por ello se ha agotado también su credibilidad. Juntas, responsabilidad ciudadana y responsabilidad social de las empresas conforman la única base sólida sobre la que se puede lograr una injerencia de la sociedad sobre la construcción de políticas públicas que atiendas al bien común; rompan con el paradigma desarrollista y con la rancia componenda cupular que sigue definiendo el interés general a espaldas de la sociedad. Se describe la aportación que desde la esfera organizacional ha permeado hasta la sociedad y sus estructuras para potenciar el cambio necesario en la ética del ciudadano de a pie que dé viabilidad a la economía ecológica. Por último, se ejemplifica el tipo de organización civil que puede coadyuvar al tránsito social local hacia estos fines con la descripción de la incipiente experiencia del Observatorio Urbano de Orizaba.

PALABRAS CLAVE: Participación. Ciudadana. Empoderamiento. Política. Pública.

\section{ABSTRACT}

This essay presents a series of arguments that aim to contribute to the theoretical construction of citizen participation, responsible as an object of study in relation to the sustainability of the development. We hold that individual citizen responsibility is a sine qua non requirement to be able to demand corporate social responsibility; we likewise argue that the representative political power has exhausted its possibilities of orienting the economic issue in the best way, and therefore its credibility has also been exhausted. Both, citizen responsibility and corporate social responsibility form the only solid basis on which society can intervene with the construction of public policies that serve to the common good; break with the development paradigm and the rancid upper echelons that continue defining the general interest behind society's back. It is described the contribution that has permeated from the organizational sphere towards the society and its structures to enhance the necessary change in the ethics of the ordinary citizen 
PARTICIPACIÓN CIUDADANA Y RESPONSABILIDAD SOCIAL PARA EL DESARROLLO SUSTENTABLE

that gives viability to the ecological economy. Finally, the type of civil organization that can contribute to the local social transit towards these aims is exemplified with the description of the incipient experience of the Urban Observatory from Orizaba.

KEY WORDS: Participation. Citizen. Empowerment. Politics. Public.

\section{INTRODUCCIÓN}

Una problemática que enfrentan las organizaciones en la actualidad, lo mismo las empresariales que las gubernamentales, es la exigencia de mostrarse socialmente responsables a la cual les confronta la realidad compleja de nuestros tiempos. Nuestra reflexión aquí está encaminada a contribuir, desde una perspectiva transdisciplinaria, a la construcción teórica de la participación ciudadana responsable, en relación con las posibilidades del desarrollo capitalista sustentable como objeto de estudio.

Para contextualizar nuestro análisis comenzaremos por reseñar el contraste entre dos paradigmas contrapuestos, desarrollismo y desarrollo sustentable. Una vez mostrada la inviabilidad del primero, veremos que a los límites propios del segundo se corresponde una propuesta alterna reciente, la llamada economía ecológica; ello permitirá la aproximación al desarrollo sustentable desde un enfoque que ve en la responsabilidad ciudadana al motor primario del necesario cambio ético que puede empoderar a la ciudadanía para el ejercicio del poder capaz de reorientar a la economía hacia la sustentabilidad de la sociedad en su conjunto. En la última sección describiremos la reciente experiencia del Observatorio Urbano de Orizaba A.C., como instancia local que creemos, ilustra el potencial de la sociedad civil organizada para refrescar la vitalidad a la experiencia del régimen democrático en México.

\section{La crisis}

Durante las últimas tres décadas ciertos conceptos torales han logrado calar hondo en la teoría y el quehacer administrativo ${ }^{1}$. Conceptos apenas emergentes hace unos cuantos años han delineado bien pronto las nuevas tendencias teóricas en el estudio organizacional; ninguno de los cuales, surgido de la arena disciplinaria económico administrativa, sino del ámbito de la

${ }^{1}$ Recomendamos consultar los trabajos compilados por Godínez et al (2013), bajo los auspicios de la Organización Latinoamericana de Administración, la Red Latinoamericana de Investigadores en Administración y el Consejo Iberopanamericano de Administración. 
PARTICIPACIÓN CIUDADANA Y RESPONSABILIDAD SOCIAL PARA EL DESARROLLO SUSTENTABLE

ciencia ecológica (Sarquís et al., 2016). Economía verde, negocios verdes, transparencia y rendición de cuentas, empoderamiento, entre otros, son términos de cuño reciente e inspiración ambientalista, aunque nada más que eso, de inspiración, ya la década de los años sesenta había ofrecido múltiples y claros indicios de los perniciosos efectos del aparato productivo/comercial mundial sobre las delicadas redes eco-sistémicas alrededor del mundo, pero sólo hasta la siguiente década las graves tendencias de deterioro ambiental global detonarían las primeras respuestas sociales, al margen del quehacer político institucional.

Además, a lo largo de los últimos cuarenta años, las preocupaciones ambientalistas de un número cada vez mayor de miembros de la comunidad científica y de un creciente sector de la sociedad, han sido asimiladas por la agenda del desarrollo sustentable que auspicia el Programa de Naciones Unidas para el Medio Ambiente (PNUMA) para devenir Agenda XXI; en gran medida, a iniciativa ciudadana de muchos países del mundo. Este proceso de transformación de las diversas reacciones iniciales a las señales de alarma en torno al creciente deterioro ambiental ha sido complejo y no ha estado exento de dificultades, lo cual legitima su estudio, afirma la pertinencia de éste y, aún más, la conveniencia de toda la atención que se le pueda brindar, pues en los mejores resultados del análisis radicarían nuevas esperanzas de renovación de la experiencia democrática capitalista.

En el afán competitivo propio del sistema capitalista, el desarrollo e innovación tecnológica se han vuelto cada vez más irreflexivos, dirigidos tan sólo por la búsqueda irrenunciable de la competitividad que exige la capacidad para la sobreproducción intrínseca del sistema. Consecuentemente se exacerba la expoliación de los recursos, la concentración del ingreso y la inequidad social. Concomitantemente, la incipiente conciencia de ciertos sectores de la sociedad sobre los problemas que todo ello ocasiona, generan una reacción opositora que intenta aglutinar esfuerzos para contrarrestar las corrosivas consecuencias de las contradicciones emanadas del sistema. En una de sus manifestaciones, dicha reacción opositora llama a la organización de grupos académicos y civiles que comparten el rechazo hacia el totalitarismo del mercado para buscar mejores y más viables alternativas a la insensatez del paradigma desarrollista que procura el crecimiento continuo, al infinito.

Efectivamente, la actual crisis global nos sitúa hoy frente a un prometedor proceso de evolución social que de pronto sugiere la inusitada oportunidad de lograr una insospechada forma de socialización de la producción; irónicamente, por la vía del liberalismo democrático que transita desde su menguante carácter representativo, hacia un incipiente corte participativo que ofrece AMADOR ANGÓN I., SARQUÍS RAMÍREZ J. I., JUÁREZ RIVERA O. 
PARTICIPACIÓN CIUDADANA Y RESPONSABILIDAD SOCIAL PARA EL DESARROLLO SUSTENTABLE

dar nuevo aliento a la experiencia democrática con una renovada funcionalidad. Ni el socialismo utópico ni el socialismo científico consideraron posible un sorpresivo empoderamiento ciudadano dentro de la institucionalidad democrática, mucho menos que éste pudiera tener como consecuencia la racionalización ecológica de la producción; algo que el primero ingenuamente suponía posible por inspiración de la buena fe propia de la filantropía pequeñoburguesa; mientras el segundo lo consideraba consecuencia dialéctica exclusiva de la historia, de modo que cualquier proposición que conllevara la posibilidad de una sociedad capitalista justa o equitativa, por ser inherentemente opuesta a la lógica instrumental del capitalismo, no podía ser sino falaz (Sarquís et al., 2014).

\section{Desarrollo Sustentable versus Desarrollismo}

El detonante de las preocupaciones en torno al creciente deterioro medioambiental fue sin duda el primer informe Meadows, Los Límites del Crecimiento ${ }^{2}$, cuyo pronóstico de escasez, hambruna y crisis social antes de finalizar el siglo XXI -si continuaban las tendencias de crecimiento demográfico y el ritmo de utilización de los recursos, principalmente petróleo y agua- lapidariamente condenaba al mundo a aprender a vivir dentro de los límites. En sus palabras: Si se mantienen las tendencias actuales de crecimiento de la población mundial, industrialización contaminación ambiental y agotamiento de los recursos, este planeta alcanzará los límites de su crecimiento en el curso de los próximos cien años. El resultado más probable sería un súbito e incontrolable descenso tanto de la población como de la capacidad industrial. (Zapiain-Aizpuru, 2016).

Tal sentencia recibió el más absoluto y unánime rechazo de economistas y políticos; sencillamente su contraposición a los objetivos de crecimiento económico motivó las más airadas reacciones y descalificaciones, pero el daño estaba hecho. Al rescate vendría la Comisión Brundtland ${ }^{3}$, cuyo informe, Nuestro Futuro Común, introdujo una primera definición del desarrollo sustentable: todas aquellas estrategias de desarrollo que permitan a las generaciones actuales resolver sus necesidades, sin afectar la capacidad de futuras generaciones, de hacer lo mismo. El corolario de "Los límites del crecimiento", i.e., no se puede

\footnotetext{
${ }^{2}$ Auspiciado por el Club Roma el informe fue el resultado del trabajo de modelación realizado por el equipo de trabajo del MIT liderado por los esposos Meadows, quienes usaron su avanzado sistema de simulación por computadora y su modelo World 3.0. El informe vio la luz en marzo de 1972.

${ }^{3}$ En abril de 1987 la Comisión presentó su informe «Nuestro futuro común» (mejor conocido como el Informe Brundtland, por el nombre del Presidente de la Comisión, Gro Harlem Brundtland, Primer Ministro de Noruega). Según el informe, no puede haber crecimiento económico sostenido sin un medio ambiente sustentable, por lo que hacer del desarrollo sustentable el cimiento del desarrollo económico y social a largo plazo.

AMADOR ANGÓN I., SARQUÍS RAMÍREZ J. I., JUÁREZ RIVERA O.
} 
PARTICIPACIÓN CIUDADANA Y RESPONSABILIDAD SOCIAL PARA EL DESARROLLO SUSTENTABLE

crecer al infinito en un mundo finito, impulsó dos corrientes contrapuestas de pensamiento económico alternas a la economía convencional, que aún hoy, se aferra al dogma central. La primera es la línea de pensamiento que agrupa académicos, políticos, economistas y conservacionistas moderados alrededor del informe de la Comisión Brundtland; estos se esmeran en elaborar los principios del desarrollo sustentable en busca de la reconciliación entre economía y naturaleza; así, a partir del informe de la Comisión, inicia en sus manos la construcción de la teoría del desarrollo sustentable encaminada a reconciliar el dogma central del paradigma desarrollista, i.e., crecimiento al infinito, con las demandas de una creciente conciencia mundial en torno a la urgencia de conservación del medio ambiente, la justicia social y la equidad económica; ideas que se constituyeron pilares del desarrollo sustentable y quedaron plasmadas en la Agenda $\mathrm{XXI}^{4}$.

La segunda corriente de pensamiento emanada del informe Brundtland nace como antítesis de la anterior; cuenta entre sus principales expositores autores como Mark Sagoff, José Manuel Naredo, Eduardo Gudynas y Antonio Elizalde, entre muchos más que critican los postulados de la economía verde y subrayan la imposibilidad teórica y práctica de la reconciliación entre la racionalidad instrumental del capital y la conservación del medio ambiente, la justicia social y la equidad económica. Para estos estudiosos, la verdadera alternativa al apocalipsis vaticinado por Donella y Denis Meadows parte y depende del rompimiento total y definitivo con el dogma del crecimiento al infinito del paradigma desarrollista. Según su análisis, la viabilidad de la civilización humana está estrictamente condicionada al aprendizaje y apropiación mayoritaria del principio fundacional de la verdadera economía alternativa, la economía ecológica ${ }^{5}$ : vivir dentro de los límites. Sin embargo, no es tan clara la propuesta metodológica para lograr tal propósito, como tampoco se encuentra este mismo, libre de dificultades semánticas ${ }^{6}$. Aun así, no se debe soslayar la invaluable aportación de los más acérrimos críticos de la economía verde. Es verdad que el debate continua y que, con toda seguridad, en ambas posturas hay aciertos y omisiones; sin embargo, a la vista de la prevalencia del pensamiento económico

\footnotetext{
4 Tanto la Agenda XXI, como la Declaración de Río sobre el Medio Ambiente y el Desarrollo y la Declaración de Principios para la Gestión Sostenible de los Bosques fueron firmadas por más de 178 países en la Conferencia de Naciones Unidas sobre el Medio Ambiente y el Desarrollo (UNCED), en Río de Janeiro, del 3 al 14 de junio de 1992. Se trata de un plan de acción exhaustivo a ser adoptado universal, nacional y localmente por organizaciones del Sistema de Naciones Unidas, Gobiernos y Grupos Principales de cada zona en la cual el ser humano influya en el medio ambiente.

${ }^{5}$ Naredo, J.M. (2002), "Economía y sostenibilidad: la economía ecológica en perspectiva, Polis No. 2, Polis Revista Latinoamericana, citado por Sarquís et al. (2016).

6 Recomendamos el brillante trabajo de Gudynas (2004). En la terminología del autor, la economía verde se corresponde con una perspectiva de sustentabilidad fuerte, mientras que la economía ecológica se corresponde con una perspectiva de sustentabilidad súper fuerte. http://polis.revues.org/7917. Santiago.

AMADOR ANGÓN I., SARQUÍS RAMÍREZ J. I., JUÁREZ RIVERA O.
} 
PARTICIPACIÓN CIUDADANA Y RESPONSABILIDAD SOCIAL PARA EL DESARROLLO SUSTENTABLE

hegemónico, la realidad económica, social y medioambiental sigue en franco deterioro alrededor del mundo y en ello nos va la vida, queramos verlo o no. De ello, ya Kalpan brindó una funesta primicia, ¿Qué hacer?

\section{Organizaciones y ciudadanía responsables, actores primarios del desarrollo sustentable}

Subrayamos la necesidad de una ciudadanía responsable, como única salida a la debacle que nos amenaza a todos por igual. A ella, deben corresponderse unas organizaciones empresariales igualmente responsables. Lo que no puede ser, es la exigencia unánime de responsabilidad social empresarial, cuando el ciudadano de a pie no se siente a sí mismo obligado a conducirse con el mismo sentido de responsabilidad frente a los demás, que el exigido a las empresas: la ciudadanía antes que las empresas, tiene el deber moral de mostrarse socialmente responsable a través de una revaloración profunda de sus hábitos de consumo y estilo general de vida7 (Sarquís et al., 2014, p. 57).

Si bien fue la alarma en torno a la crisis medioambiental la que generó reflexiones de hondo calado en las ciencias administrativas, el elemento detonante de mayor impacto sobre la proliferación reflexiva en el ámbito de la teoría administrativa ${ }^{8}$ ha sido el propio cambio en el modo de producción industrial: la línea de producción está dejando de ser la columna vertebral del sistema de producción; en la sociedad postindustrial su lugar está siendo rápidamente ocupado por la producción y gestión del conocimiento (Coriat, 2000). Una nueva revolución industrial está en marcha, ahora con máquinas de control numérico y computadoras, en lugar del motor de combustión interna. Como resultado, las empresas migran hacia nuevas formas de gestionar recursos y procesos: de la gestión por tareas a la gestión por objetivos; del trabajo en grupos a los equipos de trabajo; de la obediencia y la disciplina al autocontrol y la responsabilidad personal; del acatamiento al compromiso y del temor a la confianza; de la tarea al resultado; de la estandarización a la mejora continua; del gerente capataz al gerente líder y de las competencias técnicas a las genéricas (Anzorena, 2014). Lo nuevo en administración está cambiando a la fábrica, pero no se detiene ahí, inevitablemente permea hacia todas las

\footnotetext{
${ }^{7}$ Sería pueril negar u obstruir los aspectos positivos de la revolución tecnológica a la que aludimos antes; de lo que se trata es hacer de la participación ciudadana una estrategia para minimizar el costo socio ambiental del modo de producción dominante, cuyo fin primordial de maximizar la ganancia no repara en considerar la fragilidad de los tejidos que conforman todos los ecosistemas, como no repara tampoco en la vulnerabilidad de los tejidos sociales, $\mathrm{ni}$ se interesa en los aspectos del desarrollo humano que deben ser lo esencial de cualquier definición de progreso social (op. cit., p56).

${ }^{8}$ Ko et al. (2009) y Ramírez-Alujas (2011). ofrecen buenas revisiones de la perspectiva empresarial y de gobierno, respectivamente.

AMADOR ANGÓN I., SARQUÍS RAMÍREZ J. I., JUÁREZ RIVERA O.
} 
PARTICIPACIÓN CIUDADANA Y RESPONSABILIDAD SOCIAL PARA EL DESARROLLO SUSTENTABLE

esferas de la vida social, de modo que, el desarrollo humano que promueve en beneficio de los fines de la competitividad de las organizaciones promete, a su vez, potenciar el desarrollo democrático de las sociedades modernas a mayor plenitud (Sarquís et al., 2016). La idea central es la idea de la persona capaz de la responsabilidad compartida; este es el quid del asunto. El compromiso y la confianza ganan terreno a costa del acatamiento sumiso y del simple temor; todos los nuevos modelos de gestión subrayan la necesidad de un nuevo perfil del recurso humano: no tanto supra-especializado como supra-concientizado ${ }^{9}$.

\section{Participación ciudadana y desarrollo sustentable}

Los cambios en la línea de producción y la consecuente transformación de todos los aspectos de la vida organizacional han propiciado que la exigencia de responsabilidad social y de sustentabilidad a las organizaciones empresariales reboten impactando en forma de principios y estrategias administrativas que ofrecen un gran potencial generativo de las bases éticas que es urgente arraigar en el imaginario popular como bloques para la construcción de la moral ciudadana que mejor puede contribuir a nuestra salvación de las funestas consecuencias de la debacle ambiental y social propiciada por la irracionalidad de la lógica capitalista.

La línea de producción dependerá crecientemente de personas que necesitan ser empoderadas para el más eficaz y eficiente desempeño de sus funciones; la gente tiene que disfrutar de mayor capacidad de toma de decisiones, para lo cual debe estar continuamente informándose, capacitándose; lo mismo deben hacer, tanto los gerentes, como los jefes de todas las jerarquías para poder delegar, confiar y asumir, no tanto el mando, como el liderazgo.

Esta confianza inevitablemente está permeando ya en todas las esferas de la actividad humana promoviendo la conciencia colectiva sobre la urgente necesidad de orientar el desarrollo hacia la sustentabilidad, de modo que la propagación de las nuevas tendencias en administración promete ser herramienta importante en la lucha por la emancipación y democratización de las sociedades.

\footnotetext{
${ }^{9}$ Debemos hablar de una responsabilidad social posible, a partir de la ciudadanía real en las condiciones concretas de desarrollo socioeconómico y de cultura política que limitan nuestro acercamiento a los contornos de ambos ideales, los cuales son materia de la moral, la ciencia de la virtud; idealmente, la responsabilidad social es la virtud de tomar decisiones de manera consciente, asumiendo el deber de responder por las consecuencias de las mismas. Un elemento necesario de este ideal de responsabilidad social es la libertad, pues ésta determina que alguien pueda realizar cualquier acción porque así conviene a los criterios del bien común, y no por efecto de una disposición coercitiva (Sarquís y Solís, 2013).
} 
PARTICIPACIÓN CIUDADANA Y RESPONSABILIDAD SOCIAL PARA EL DESARROLLO SUSTENTABLE

Conforme las organizaciones buscan la competitividad al mismo tiempo que enfrentan el reto de armonizar su quehacer productivo/comercial con las exigencias de la nueva conciencia sobre la agenda para el desarrollo sustentable impulsada globalmente desde la ONU, las instituciones de gobierno y de la sociedad civil también están procurando dar respuesta a los retos de armonizar la vida social con lo económico, tanto como con lo medioambiental, a modo de encaminar el desarrollo por la ruta de la sustentabilidad.

Acemoglu y Robinson (2012) argumentan que el Estado de Derecho es esencial para crear el círculo virtuoso que puede transformar a las sociedades extractivas en inclusivas. Las instituciones deben ser inclusivas, pues donde son extractivas no sirven al interés general, sino al interés de las élites que mantienen a la mayoría de la población sumida en la miseria. La igualdad de oportunidades brinda la doble virtud de reducir los conflictos sociales y de conseguir que se multipliquen los emprendedores e innovadores capaces de llegar al mercado. Los autores concluyen que el emprendimiento y la innovación sólo son posibles en países inclusivos. Para posibilitar la concreción de tal escenario social, el ascenso del autocontrol y la responsabilidad de la persona por sobre los viejos valores paradigmáticos de la obediencia y la disciplina son requisito más que necesario.

El concepto de ciudadanía está claramente ligado al de ciudad: espacio colectivo donde lo individual integra lo comunitario en estructuras, funciones y tensiones: nadie es ciudadano al margen de sus vínculos con la comunidad: se es ciudadano sólo en convivencia ${ }^{10}$ (Sarquís y Solís, 2013). Las ciudades son hoy los asentamientos humanos más importantes a nivel mundial; por lo que el modo de vida urbano es la tendencia dominante en nuestros tiempos. Las sociedades han pasado de ser prominentemente rurales a urbanas en los últimos doscientos años, a raíz del advenimiento de la era industrial. Ante esta nueva realidad urbana de la mayoría de la población mundial, la ONU exhorta a todas las naciones a sumarse al esfuerzo por encausar el desarrollo por los criterios de la sustentabilidad, desde lo local hasta lo regional.

Los planteamientos ONU-Hábitat destacan el hecho de que, en un contexto de sociedades más urbanas, se atribuye cada vez más peso a la intervención ciudadana como requisito para revertir las tendencias actuales de deterioro social y medioambiental. Por eso mismo, la

\footnotetext{
${ }^{10}$ Idoya-Zorroza (2008, citada por Sarquís y Solís, 2013) lo observa elegantemente: No sólo es posible que el ser humano conviva, sino que no puede vivir si no es conviviendo en una respectividad esencial con el mundo y con los demás. La positiva indefensión e insuficiencia del ser humano le hacen ser esencialmente dependiente, luego, plantear los fines y valores que la persona ha de buscar, desde el ideal individualista es hacerle vivir en la superficie de su propia existencia, y no una existencia plena (op. cit. p34). AMADOR ANGÓN I., SARQUÍS RAMÍREZ J. I., JUÁREZ RIVERA O. 
PARTICIPACIÓN CIUDADANA Y RESPONSABILIDAD SOCIAL PARA EL DESARROLLO SUSTENTABLE

legislación se adecúa a estas exigencias y se globaliza el marco jurídico que auspicia la participación ciudadana en los procesos de construcción de la política pública.

En México, hacia los años ochenta se inician las reformas constitucionales que poco a poco han logrado abrir importantes espacios a la participación ciudadana ${ }^{11}$. Ésta presupone un marco jurídico que la promueva y cobije, la prevalencia de un respeto a las garantías individuales, el acceso irrestricto a la información pública y una sólida confianza en las instituciones. Sin estás condiciones, no es posible la libre participación ciudadana (Serrano, 2015).

En México, estas premisas tienen diversos grados de desarrollo. El marco jurídico es quizá el más adelantado, con todo y que aún es más que perfectible, puede afirmarse que ya no es limitante. El acceso a la información no es todo lo pronto y expedito que se desearía, persisten inercias y resistencias a la transparencia, pero cada vez es más propicio. El respeto a las garantías es cuestionable; sin embargo, ni los reiterados reportes de violación a los derechos humanos, ni los crímenes contra periodistas ni otros atropellos detienen ya la avalancha ciudadana. Quizá el mayor rezago estriba en la precaria confianza de los ciudadanos en sus instituciones democráticas; por eso la participación ciudadana sigue siendo muy reducida.

A pesar de que contamos con una Ley de participación ciudadana, con un instituto de acceso a la información, con un artículo 115 constitucional reformado que ha trasladado mucho más capacidad de gobierno a los municipios; consejos sociales de participación, institutos municipales de planeación, consejos municipales de planeación del desarrollo; a pesar de contar con una Ley Federal de apoyo a las actividades de las organizaciones de la sociedad civil, nuevas de modalidades de democracia semidirecta como el referéndum, el plebiscito y la consulta ciudadana presentes en buena parte del país, incluso la revocación de mandato en dos estados; a pesar de múltiples experiencias en presupuesto participativo y muchas más, la Encuesta Nacional sobre Cultura Política y Prácticas Ciudadanas del 2012 reveló que 84\% de nuestra población confiesa estar poco o nada interesada en política; un $62 \%$ declara poco interés en los problemas de su comunidad, el $71 \%$ declara que nunca ha asistido a reuniones que tienen por objeto resolver problemas de su colonia y el $79 \%$ nunca ha participado en ninguna forma de manifestación a favor o en contra del gobierno.

\footnotetext{
${ }^{11}$ Entendida ésta como la intervención organizada de ciudadanos individuales o de organizaciones sociales o civiles en los asuntos públicos, que se lleva a cabo en espacios y condiciones definidas.

AMADOR ANGÓN I., SARQUÍS RAMÍREZ J. I., JUÁREZ RIVERA O.
} 
PARTICIPACIÓN CIUDADANA Y RESPONSABILIDAD SOCIAL PARA EL DESARROLLO SUSTENTABLE

El bajísimo nivel de confianza en las instituciones puede ser señalado como la principal causa de esta apatía. Particularmente las pertenecientes al poder judicial son señaladas como las menos confiables; sin que ello exonere al conjunto restante (Serrano, 2015).

El reverso de la moneda es que las instituciones nacionales tampoco confían mucho en la ciudadanía; de ahí el excesivo número de leyes, normas y reglamentos. El arcano escepticismo del mexicano es atributo de todos los mexicanos, no nada más del ciudadano de a pie (Sarquís y Sarquís, 2012). Cada vez más personas coinciden en que no será ningún gobierno, ningún partido político, ningún líder particular, el que recate al país del estancamiento, de la amenaza del ominoso futuro de frente a la crisis global; ha de ser sólo un amplio sector de la población empoderado por un firme sentido de responsabilidad social que le lleve a inmiscuirse activamente, no sólo en la fiscalización de la función pública (Maldonado y Gertz, 2011), sino en la construcción misma de la política pública, como ha sugerido recientemente Jorge Castañeda (2016), al referirse a la construcción de una agenda ciudadana a ser confiada a un candidato verdaderamente independiente.

Desde el plano internacional, la ONU ha provisto al concierto de las naciones de los instrumentos que pueden dar viabilidad a una ciudadanía socialmente responsable. Tal es el sistema de los observatorios urbanos: red mundial de información para la construcción de capacidades creada por el Programa de Naciones Unidas para los Asentamientos Humanos (ONU-Hábitat) ${ }^{12}$ con el propósito de impulsar, tanto la Agenda Hábitat, como la Agenda XXI en el ámbito nacional y local.

Los objetivos de la red de observatorios urbanos incluyen: estimular procesos de consulta de base amplia para ayudar a identificar e integrar las necesidades urbanas de información; ayudar a desarrollar capacidades para la recolección, manejo y aplicaciones de política de información urbana, centrada en indicadores y mejores prácticas; proveer información y análisis a todos los interesados para lograr una participación más efectiva en la toma de decisiones urbanas y, compartir información, conocimientos y conocimientos especializados usando tecnología e infraestructura de información modernas.

En 2010, había 33 observatorios urbanos instalados en 31 municipios en 14 estados de la República Mexicana, con influencia sobre una población cercana a los 23 millones de

\footnotetext{
${ }^{12}$ Aquí reseñamos libremente los postulados contenidos en el programa de la ONU conocido bajo el nombre de Agenda Habitat (http://www.un.org/spanish/ag/habitat/agenda_s.htm). AMADOR ANGÓN I., SARQUÍS RAMÍREZ J. I., JUÁREZ RIVERA O. 
PARTICIPACIÓN CIUDADANA Y RESPONSABILIDAD SOCIAL PARA EL DESARROLLO SUSTENTABLE

habitantes ${ }^{13}$. Todos adscritos al programa ONU-Hábitat, conforman una red que interactúa estrechamente con la SEDESOL.

\section{Observatorio Urbano de Orizaba (OUO), una incipiente experiencia local}

El municipio de Orizaba, Veracruz, se ubica en la zona de las altas montañas del centro del estado. Un municipio pequeño, (28 km²), 100\% urbano, con aproximadamente 130,000 habitantes. Forma parte de un corredor conurbado junto con los municipios de Río Blanco, Nogales y Mendoza, al poniente; Ixtaqzoquitlán al oriente, Rafael Delgado y Huiloapan, al sur e, Ixhuatlancillo, Mariano Escobedo y Atzacan, al norte. En total, unas 250,000 personas en una zona metropolitana compleja en más de un sentido.

La región fue una importante sede fabril por mucho años, pero ya no lo es; no sólo por el cierre de todas las fábricas textiles, sino porque las grandes industrias que aún operan ${ }^{14}$, se han orientado a un continuo proceso de modernización y automatización que ha resultado en la disminución significativa de su planta laboral, de modo que, de cada diez empleos que había en 1990, han desaparecido siete. El desempleo es el más grave de los problemas en la región, situación de la que en los últimos años se ha aprovechado el crimen organizado, sumándose así al flagelo de la falta de ocupación, la migración y la inseguridad. En este contexto, pronto habrán sido diez años de administración local que han marcado un profundo cambio en la fisonomía y en la dinámica del municipio. El consenso de la opinión pública es que las últimas tres administraciones han transformado completamente a la ciudad, la cual, a propósito, obtuvo hace dos años la denominación de Pueblo Mágico. De ser un lugar en ruinas apenas iniciado el nuevo siglo, de ser el fantasma de la otrora "Manchester veracruzana", Orizaba se ha convertido muy pronto en un destino turístico nacional e internacional15.

Actualmente, el OUO fundado en octubre de 2015, se encuentra debidamente protocolizado ante la notaría pública número dos en la ciudad ${ }^{16}$; su mesa directiva se compone de cinco integrantes y su membresía incluye 20 personas. A la fecha, ha organizado un taller de desarrollo metropolitano sustentable, ha impartido pláticas y talleres de planeación a un total de

\footnotetext{
13 Datos disponibles en http://www.merida.gob.mx/observatorio/pdf/encuentros/octavo/nuevolared.pdf (recuperado el 19 de marzo de 2017).

${ }^{14}$ Como Cervecería del Grupo Cuauhtémoc-Moctezuma (hoy Heineken), Cementos Apasco, Kimberley-Clark y Proquina.

15 Según funcionarios de la Dirección de Desarrollo Económico Municipal, datos preliminares cifran el incremento en el número de visitantes que permanecen en Orizaba más de una noche se ha incrementado en 350\% (comunicación personal).

${ }^{16}$ Cuyo responsable es el Lic. José Antonio Márquez González. AMADOR ANGÓN I., SARQUÍS RAMÍREZ J. I., JUÁREZ RIVERA O.
} 
PARTICIPACIÓN CIUDADANA Y RESPONSABILIDAD SOCIAL PARA EL DESARROLLO SUSTENTABLE

más de 180 jefes de manzana y se ha visto involucrado ya en dos procesos de participación ciudadana relacionados con la definición de la política pública municipal. En diciembre de 2016, por iniciativa propia ${ }^{17}$, el OUO lanzó una convocatoria abierta a la participación ciudadana con el objeto de generar información útil para la construcción del Plan Municipal de Desarrollo 2018$2021^{18}$. En total fueron capturadas 246 propuestas sobre temas de medio ambiente, economía o sociedad. Los resultados preliminares sugieren que las personas participantes tienen mejor idea de lo que desean que haga la autoridad en lo que se refiere a medio ambiente y a los temas sociales como seguridad, movilidad, transporte público, que en lo referente al tema económico. A este respecto, es claro que la demanda de empleo es de las más recurrentes, pero qué hacer en concreto, cómo resolver el problema de la falta de oportunidades, eso no resulta tan claro; además de exigir empleo, no parece haber una idea definida de lo qué es y qué no es atributo de la autoridad local, ni de qué es lo mejor para orientar el esfuerzo de dicha autoridad a la generación de riqueza.

Actualmente, el OUO se dedica a la preparación de un foro ciudadano a llevarse a cabo en la primera quincena de mayo. En este foro, una selección de las veinte mejores propuestas capturadas será presentada por los propios proponentes ante el público general que será convocado y al cual los candidatos de los partidos contendientes en el proceso electoral de junio, serán invitados a participar y firmar su compromiso serio de tomar en cuenta la voz ciudadana al momento de elaborar el Plan Municipal de Desarrollo para la siguiente administración municipal. Este novedoso ejercicio de participación ciudadana logró, a pesar del poco tiempo y los escasos recursos empleados, una respuesta importante, pues aunque fueron sólo 246 propuestas, dado que muchas fueron grupales en realidad la representatividad de la muestra supera las mil personas, alrededor de1.25\% del padrón electoral del municipio.

Un futuro reporte abordará de manera exhaustiva los resultados del ejercicio; por ahora, el motivo de reseñar su formulación y realización en este espacio se limita a brindar un ejemplo de participación ciudadana en un proceso político. La valoración que el propio OUO hace de este primer ejercicio de participación ciudadana en política es muy positiva. Un primer ejercicio que no es del todo ignorado, que genera el interés de los medios, que recibe considerable atención en redes sociales, resulta refrescante y prometedor.

\footnotetext{
17 Inspirada por la preocupación de que los resultados de la elección de este año pudieran poner al mando a alguien -como tantos hay- que quisieran tan sólo aprovecharse de la nueva situación financiera boyante que goza el municipio o sencillamente abortar los programas vigentes por razones ajenas al bienestar general.

${ }^{18}$ La convocatoria y sus detalles, así como el formulario que los participantes debían llenar se encuentran disponibles en el portal web del OUO: www.observatoriourbanoorizaba.org AMADOR ANGÓN I., SARQUÍS RAMÍREZ J. I., JUÁREZ RIVERA O. 
PARTICIPACIÓN CIUDADANA Y RESPONSABILIDAD SOCIAL PARA EL DESARROLLO SUSTENTABLE

Por último, es menester mencionar que el ejemplo del OUO es más recomendable que no recomendable; no sólo porque trabaja de conformidad con los lineamientos del programa mundial de sustentabilidad del desarrollo: la agenda siglo XXI, ONU-Hábitat; no nada más porque procura mejores políticas públicas a través de la generación de información útil; aunque sería inadmisible pretender que bastara, ¿qué información puede ser más útil que el sentir ciudadano? La del OUO es una experiencia recomendable, porque se trata de una organización de la sociedad civil que, haciendo uso del marco jurídico actual, haciendo valer el derecho a la información y venciendo el temor a cualquier forma de persecución o represión, procura coadyuvar a la credibilidad de las instituciones, pretende abonar a la confianza ciudadana en las entidades y procesos institucionales. El OUO encarna el anhelo de una injerencia organizada directa de la sociedad, con objetivos y metas concretas y medibles, sobre el diseño y elaboración de pautas de política pública definidas desde la perspectiva de la gente común, al margen de la lucha por el poder político, sin el lastre de los compromisos capaces de mutilar mejores intenciones, de frente a todo el conglomerado social con absoluta transparencia y comprometida con la lucha por materializar esas pautas en los planes municipales de desarrollo, su seguimiento y medición de sus alcances, la vigilancia y, en su caso la denuncia de cualquier desviación en manos de los ejecutantes de esas políticas. No es de otra cosa que va la democracia participativa.

\section{REFERENCIAS BIBLIOGRÁFICAS}

Acemoglu, D. y Robinson, J.A. (2012). Why nations fail. The origins of power, prosperity and poverty. London: Profile Books.

Coriat, B. (2000). El taller y el robot: ensayos sobre el fordismo y la producción en masa en la era de la electrónica. México. Siglo XXI Editores.

Anzorena, O. (2014). 8 nuevas tendencias de gestión empresarial. Gestiopolis. Recuperado de http://www.gestiopolis.com/administracion-estrategia-2/8-nuevas-tendencias-gestionempresarial.htm 
PARTICIPACIÓN CIUDADANA Y RESPONSABILIDAD SOCIAL PARA EL DESARROLLO SUSTENTABLE

Castañeda, G. J. (2016). Sólo así: por una agenda ciudadana independiente. México: Penguin Random House Grupo Editorial México.

Cravino, L.M. (2012). 10 tendencias que impactarán sobre la gestión del capital humano. Petrotecnia. Junio 2012, pp. 10-18. Recuperado de http://www.petrotecnia.com.ar/junio12/sinpublicidad/10Tendencias.pdf

Didriksson, A. (2000). La Universidad del futuro. Relaciones entre la educación superior, la ciencia y la tecnología. México: Plaza y Valdez Editores, UNAM.

Godínez, H., López, Blanca E., \& Chirino, A. (2014). Organizaciones Inteligentes. Gobernabilidad y Gobernanza en Entornos Sustentables de Latinoamérica. Organización Latinoamericana de Administración, Red Latinoamericana de Investigadores en Administración, Consejo Iberopanamericano de Administración.

Gudynas, E. (2002). Ecología, Economía y Ética del Desarrollo Sostenible. (5ª ed.). Montevideo: Coscoroba Ediciones.

Kaplan, R.D. (1994). The coming anarchy, en The atlantic monthly, 273(2), 44-76. Recuperado de: http://hope.nps.edu/Academics/Institutes/Cebrowski/Docs/Rasmussendocs/The\%20 Coming\%20Anarchy.pdf (citado por Sarquís et al., 2016).

Ko, R. K., Lee, S. S., \& Lee, E. W. (2009). Business process management (BPM) standards: a survey. Business Process Management Journal, 15(5), pp. 744-791.

Maldonado Venegas, L., Manero Gertz, A. (2011). Democracia real y poder ciudadano. México: Porrúa.

Ramírez-Alujas, Á. (2011). Gobierno abierto y modernización de la gestión pública: tendencias actuales y el (inevitable) camino que viene. Reflexiones semifinales. Revista Enfoques, 9(15), pp. 99-125.

Sarquís, J.I., y Sarquís, D.J. (2012). Los avatares de la democracia en México: los mexicanos y sus procesos de construcción social. Razón y Palabra. ITESM, México. 79, p. 21.

Serrano Rodríguez, Azucena. (2015). La participación ciudadana en México. Estudios políticos (34), pp.

93-116.

Recuperado de. 
PARTICIPACIÓN CIUDADANA Y RESPONSABILIDAD SOCIAL PARA EL DESARROLLO SUSTENTABLE

http://www.scielo.org.mx/scielo.php?script=sci_arttext\&pid=S018516162015000100005\&ln $g=e s \&$ lng $=e s$

Sarquís, J.I., Solís Alemán. (2013). Ciudadanía y Responsabilidad Social I. Empoderamiento ciudadano para el rescate del Estado democrático. Multidisciplina (16), pp. 27-46.

Sarquís, J.I., Lagunes, P., Solís Alemán. (2014). Ciudadanía y responsabilidad social II. El caso de las empresas, del slogan al compromiso con la praxis. Multidisciplina (17), pp. 50-70.

Sarquís, J.I., Carrera, R., De los Santos, C. (2016). El nuevo antiguo régimen. POLIS Revista Latinoamericana, 46. Recuperado de http://polis.revues.org/11779

Sarquís, J.I., Herrera, G. A., García, C. Messina, M. (2016). Pensamiento administrativo emergente y su impacto sobre el desarrollo humano, empresarial y social. En IV Congreso Internacional de Investigación e Innovación Multidisciplinario. UCEC. pp. 1386-1398. Cortazar, Gto: Permusa.

Zapiain Aizpuru, M. (2006). Los límites del crecimiento: informe al club de Roma sobre el predicamento de la humanidad Meadows, D.H.; Meadows, D.L.; Randers, J; Behrens, W. (1972). Recuperado de https://www.google.com.mx/webhp?sourceid=chromeinstant\&ion=1\&espv=2\&ie=UTF8\#q=p rimer+informe+meadows+los+limites+del+crecimiento 